Article

\title{
Environmental and Health Impact of Electric and Hydrogen Light Vehicles: the case of an Italian Small City
}

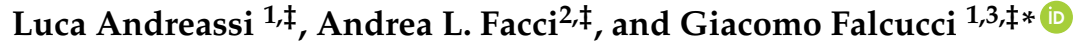 \\ 1 Dept. of Enterprise Engineering "Mario Lucertini" - University of Rome "Tor Vergata" - Via del Politecnico 1, \\ 00133 Rome (Italy); luca.andreassi@uniroma2.it \\ 2 DEIM - School of Engineering - University of Tuscia - Largo dell’Universitá, 01100 Viterbo (Italy); \\ andrea.facci@unitus.it \\ 3 John A. Paulson School of Engineering and Applied Sciences - Harvard University - 33rd Oxford St., 02138 \\ Cambridge - MA (USA); giacomo.falcucci@uniroma2.it; falcucci@g.harvard.edu \\ * Correspondence: giacomo.falcucci@uniroma2.it; falcucci@g.harvard.edu \\ $\ddagger \quad$ These authors contributed equally to this work.
}

\begin{abstract}
As the emission regulations get more and more stringent in the different fields of energy and environmental systems, the electric and fuel cell vehicles (FCV) have attracted growing attention by automakers, governments, and customers. Research and development efforts have been focused on devising novel concepts, low-cost systems, and reliable electric/fuel cell powertrain. In fact, electric and fuel cell vehicles coupled with low-carbon electricity sources offer the potential for reducing greenhouse gas emissions and exposure to tailpipe emissions from personal transportation. In particular, Pedal Assisted Bicycles (PAB) popularity is rising in urban areas due to their low energy consumption and environmental impact. In fact, when electrically moved, they are zero emission vehicles with very low noise emissions, as well. These positive characteristics could be even improved by coupling a PAB with a fuel cell based power generation system, thus increasing the vehicle autonomy without influencing their emissions and consumption performances.

In this paper, four types of vehicles are compared from an environmental and accessibility point of view: conventional car, bus, electric $\mathrm{PAB}$ and hydrogen fuel cell PAB; for such vehicles, the respective utilization stages are accounted for, i.e. without considering the manufacturing process. The analysis has been carried out comparing different vehicles performance along different routes of an Italian middle-size city, Viterbo, which represents a very good pilot case as its Municipality is adopting many solutions suggested by European Union (EU) through the planning tool called Sustainable Energy Action Plan (SEAP). The comparison is based on an ad-hoc developed mathematical procedure, which includes environmental (greenhouse gas and air pollution emissions), health (pollutants toxicity levels) and accessibility time (waiting times) indicators. According to this analysis, electric and fuel cell PAB exhibit interesting advantages over the other vehicles. However, the global economic efficiency of electric or fuel cell apparatus depends substantially on the exploited source of electrical energy.
\end{abstract}

Keywords: Electric Vehicles; Fuel Cell Vehicles; Sustainable Mobility; Mobility Habits; Sustainable Urban Transportation. 


\section{Introduction}

The transport pollution is one of the main causes of world-wide modern ecological problems. According to the Transport Briefing of the European Environment Agency (EEA) published in February 2015 [2], transport is responsible for 25\% of the European Union (EU) greenhouse gas emissions and contributes significantly to air pollution, noise and habitat fragmentation. $95 \%$ of traveled kilometers, both passenger and freight, in the EU are powered by oil derived fuels. Emissions of air pollutants from transport have generally reduced over the past two decades, but still around $90 \%$ of city dwellers in the EU are exposed to air pollutants at levels deemed harmful to health by the World Health Organization (WHO), and transport is a large contributor to this. At the same time the trends for transport greenhouse emissions show significant reductions starting from 2007 onward, which is due to different government policies for lowering the transport pollution level. Considering the traditional transportation system, it is worth of noting that a traditional car emits approximately 19 pounds of $\mathrm{CO}_{2}$ gas per gallon of fuel burned. According to the EPA, [1], that rounds up to a ton of $\mathrm{CO}_{2}$ every year, for a small car. A midsize car or SUV on the other hand, will release 1.3 tons, and a full-size SUV or truck will put out 1.9 tons. These are conservative estimates per capita, but it is known that a single car can emit up to 6 tons of carbon dioxide in a year in actual urban cycles, [3,4]. On the other hand, buses are much larger than most vehicles and only get about 7-12 miles per gallon. Any bus accident attorney can attest to the power and weight of these vehicles, but more power does not necessarily imply a larger carbon footprint. A single school bus can eliminate up to 36 cars. Nevertheless, even if better than cars, bus environmental impact still remains [4].

In recent decades, the promotion of non-motorized transport solutions has increased as part of more sustainable eco-mobility vision. In this scenario Electric Veichles (EV's) and Fuel Cell Vehicles (FCV's) seem to be possible candidates to become a real solution to the transportion problem, due to the environmental potential of their innovative technologies, [5-7].

Among these pioneering devices, however, EV's can reduce but not eliminate urban air pollution, [8]. They, in fact, can reduce to zero the local sources of air pollution, including nitrogen oxides (NOx) and sulphur oxides (SOx), but when taking a closer look to the data, it becomes clear that they would not eliminate the majority of local particular matter emissions which are produced when cars are driven, via brake wear, tire wear and road abrasion. Nevertheless, also based on data published by the United Kingdom's National Atmospheric Emissions Inventory, it could be concluded that EV's can reduce urban pollution caused by transport more than $82 \%$ if they fully replace the oil derived fuel cars. This conclusion excludes the pollution caused by the energy and batteries production processes.

Among EV's, the most wide spread implementation is that of electrical bikes, due to the fact that they are low-cost, low-polluting and produce health benefits, [9]. EV's (and electric bikes in particular) are extremely efficient and emit near zero emissions at the point of use. They provide high level of mobility and use little energy, emitting low levels of pollution per vehicle (passenger) kilometer traveled, even compared to fully occupied buses. This could be considered a positive development as in the most European cities air quality is strongly affected by transportation.

E-bikes do use electricity whose generation amounts of conventional pollutants and green house gases [10], but they move emissions from tailpipes to power plants that are often away from urban areas, further reducing the overall human exposure to pollutants. Even if not as diffused as EV's, FCV have the potential to significantly reduce our dependence on foreign oil and lower harmful emissions that contribute to climate change. FCV's run on hydrogen gas rather than gasoline and emit no harmful tailpipe emissions. Several challenges must be overcome for them to be competitive with conventional vehicles, but their potential benefits are substantial [1,11]. In this case the main issue is the hydrogen production methodology together with the consequent costs and emissions. Other issues are related to the high cost of the fuel cell, the hydrogen storage and transportation, and life cycle of the fuel cells. Whatever is the final choice, surely accessibility has to be guaranteed. The primary benefit of any transportation mode is, in fact, the mobility and accessibility increase. In the case of bicycles, for example, it provides much higher levels of mobility and thus accessibility with respect to 
bus or private car. Mobility and accessibility is dependent upon the urban layout, distribution of land uses and transportation infrastructure. Ease of movement or operating speeds of various modes can describe differences in mobility. It is important to remark that job accessibility has been identified as a major contributor to poverty in developing countries and is an essential impact to be considered in the development of any transportation policy [13]. Under this scenario, Public Administrations (PA) in Europe (and in Italy) are called by EU to play a fundamental role. Specifically, the Municipality must promote sustainable mobility and reduce the need for transportation through:

- the possibility of door-to-door transfers in the urban area promoting the bicycle use for short distances through the enhancement of cycle paths in the territory;

- promoting the use of public transport and securing stops to facilitate their use;

- creation of safe home school paths to encourage the bycicle use or to move by feet;

- promotion of the modernization of private vehicles and purchasing of electric vehicles through the installation of charging stations.

This paper compares the environmental and safety impacts of electric bicycles and hydrogen-fueled bicycles to those of alternative modes of transportation, such as public bus, or personal cars. In particular for the FCV, these bicycles have been realized and experimentally tested in the research laboratories of University of Naples "Parthenope". The research also analyzes the benefits of electric and $\mathrm{H}_{2}$ two-wheelers in terms of increased mobility and accessibility, accounting for their speed and operating range. The analysis has been carried out comparing different vehicles performance when considering different routes of an Italian city, Viterbo, which represents a very good pilot case, as its Municipality is adopting many solutions suggested by EU through the SEAP planning tool, [10].

\section{Material \& Methods}

\subsection{Electric bicycles}

Electric bicycles are extremely efficient and emit near zero emissions at the point of use. They provide high level of mobility and use little energy. Electric bikes use very little electricity and tend to decrease exposure to pollution as their environmental impacts largely result from vehicle production and electricity generation outside of urban areas. E-bikes outperform other motorized transport modes, including bus transit, on energy efficiency and greenhouse gas emissions rates per passenger kilometer, considering the complete life cycle environmental impact, [12]. Even in Europe, and not only in China, e-bikes are penetrating the market because they offer an additional value relative to standard bicycles. The large-scale adoption of electric two-wheelers can reduce traffic noise and road congestion but may necessitate adaptations of urban infrastructure and safety regulations. The great advantage of electric bikes (EB's) is that they are recharged simply by exploiting standard wall electrical plugs. This is a great advantage as there is no need for dedicated refuelling/recharging infrastructure. Most electric bikes, in fact, are characterized by removable batteries and chargers so that they can be transported into an apartment or workplace and recharged during the day or night. Going in a deeper detail, the Italian energy mix is reported in Tab. 1.

The major issue connected to e-bikes is that they use lead acid batteries, which emit lead into environment through various production processes. This represents a major environmental concern, but it will not be addressed in the present work.

It is to remark that present-day e-bikes have a range greater than 50 kilometers on a single charge, so making e-bikes suitable for urban transportation. Finally, it is worth of noticing that, before drawing any conclusion, an integrated urban mobility planning that accounts, e.g., for the local electricity mix, infrastructure characteristics, and mode-shift behavior, should be conducted, [14].

\subsection{FC-bike}

The hydrogen Fuel Cell Bicycle (FCB) is another growing category of alternative fuel vehicles. Similar to e-bikes , FCB's also utilize electric motors for propulsion. However, instead of batteries, the 
Table 1. Italian Energy Mix, 2015.

\begin{tabular}{|c|c|}
\hline Energy production: & $\begin{array}{l}35.5 \text { Mtoe (biofuels and waste } 32.2 \% \text {; oil } 15.9 \% \text {; natural gas } 15.6 \% \text {, } \\
\text { geothermal } 15.4 \% \text {, hydro } 10.6 \% \text {, solar } 6.6 \% \text {, wind } 3.6 \% \text {, coal } 0.1 \% \text {, } \\
+17.7 \% \text { since } 2005 \text { ) }\end{array}$ \\
\hline TPES: & $\begin{array}{l}\text { 150.7 Mtoe (natural gas } 36.7 \% \text {, oil } 34.2 \% \text {, biofuels and waste } 9.7 \% \text {, } \\
\text { coal } 8.2 \% \text {, geothermal } 3.6 \% \text {, electricity net imports } 2.6 \% \text {, hydro } 2.5 \% \text {, } \\
\text { solar } 1.6 \% \text {, wind } 0.8 \% \text {, } \\
-19.1 \% \text { since } 2005 \text { ) }\end{array}$ \\
\hline TPES per capita: & 2.5 toe (IEA average: 4.5 toe) \\
\hline TPES per GDP: & 0.08 toe/USD 1000 PPP (IEA average: 0.11 toe/USD 1000 PPP) \\
\hline Electricity generation: & $\begin{array}{l}280.7 \text { TWh (natural gas } 38.3 \% \text {, coal } 16.6 \% \text {, hydro } 15.6 \% \text {, solar } 9.3 \% \text {, } \\
\text { biofuels and waste } 7.8 \% \text {, wind } 5.2 \% \text {, oil } 4.8 \% \text {, geothermal } 2.2 \% \text {, } \\
-5.4 \% \text { since 2005) }\end{array}$ \\
\hline $\begin{array}{l}\text { Electricity and heat generation } \\
\text { per capita: }\end{array}$ & 5.6 MWh (IEA average: $9.9 \mathrm{MWh}$ ) \\
\hline
\end{tabular}

fuel cells on-board generate the required electricity by processing compressed hydrogen gas. Single fuel cells are only capable of producing small electrical potentials. Thus, for their technological exploitation, several single-cells must be connected together in a stack. There has been very limited commercial production of FCB's, [15]. With respect to EB's, FCB's present some attracting characteristics. First of all, they do not suffer from specific limitations connected to the EV's capability to travel only short distances. Another favorable issue is connected to the refuelling time which is only 3 to 5 minutes, which is comparable to that of conventional internal combustion engine vehicles and is enormously lower than the EV's recharging time. From an environmental point of view, as already discussed, in terms of the creation and utilization of fuel, FCV's appear to create less greenhouse gas ( $45 \%$ ) and air pollution $(70 \%)$ emissions compared to conventional vehicles. Depending on the energy generation process, FCV's also appear to be comparable to EB's. It is worth of noticing that in this paper we are going to face just the environmental impacts connected to the use phase. Nevertheless, if we consider also the production phase, some negative issues arise. In fact, the production of FCV's generates a significantly greater amount of greenhouse gas emissions and more than twice as much as the other types of vehicles [16]. A similar trend can be seen for air pollution emissions, as well.

\subsubsection{Experimental Setup: Hy-Bike Energy System}

The core of the energy system of our FCB is the H500 PEM Fuel Cell stack by H2Planet, [17]. Table 2 reports the main physical and chemical parameters of this stack.

The chosen stack has been tested in the Laboratory of Energy Systems at the University of Naples "Parthenope" before being installed on the FCB prototype. Figure 1 shows the polarization and power curve of the stack, according to the tests performed on our test-bench. The plot reports the data according to five experimental tests, performed by scanning the output current of the fuel cell by means of a Chroma 63201, $2.6 \mathrm{~kW}$ electronic load. The data obtained according to these tests perfectly match with the polarization and power performance declared by the manufacturer, [17]. 
Table 2. Main physical parameters of the chosen PEM Fuel Cell stack.

\begin{tabular}{l|l}
\hline Type of Cell & PEM \\
Cell number & 36 \\
Nominal Power & $500 \mathrm{~W}$ \\
Nominal Performance & $21.6 \mathrm{~V} 24 \mathrm{~A}$ \\
$\Delta$ V range & $19-35 \mathrm{~V}$ \\
Ambient Operating Temperature & $5-30^{\circ} \mathrm{C}\left(41-86^{\circ} \mathrm{F}\right)$ \\
Cell maximum Temperature & $65^{\circ} \mathrm{C}\left(151^{\circ} \mathrm{F}\right)$ \\
$\mathrm{H}_{2}$ Pressure & $0.45-0.55 \mathrm{bar}$ \\
$\mathrm{H}_{2}$ Purity & $99.995 \%$ dry $\mathrm{H}_{2}$ \\
Humidification & Self-humidified \\
Cooling & Air (integrated cooling fan) \\
Stack Weight (with fan \& casing) & $2800 \mathrm{~g}( \pm 50 \mathrm{~g})$ \\
Controller Weight & $400 \mathrm{~g}( \pm 30 \mathrm{~g})$ \\
Cell Dimensions & $215 \times 125 \times 180 \mathrm{~mm}$ \\
Flow rate at maximum output & $71 / \mathrm{min}$ \\
Start up time & $\leq 30 \mathrm{~s}($ ambient temperature) \\
Stack Efficiency & $40 \% 21.6 \mathrm{~V}$ (full power) \\
Low Tension Protection & $18 \mathrm{~V}$ \\
Overcurrent Protection & $30 \mathrm{~A}$ \\
Overtemperature Protection & $65{ }^{\circ} \mathrm{C}$ \\
\hline
\end{tabular}

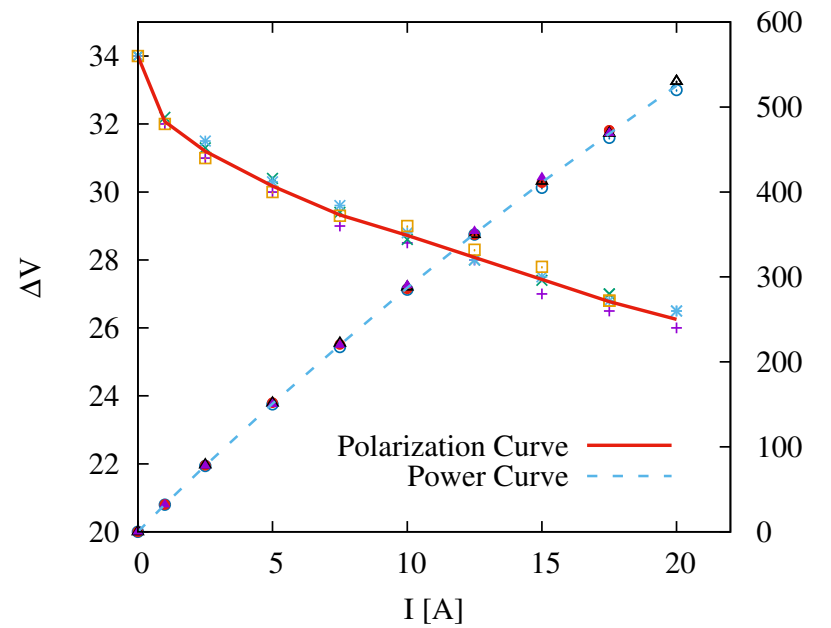

Figure 1. Polarization and Power Curves for the chosen PEM Fuel Cell stack. The points correspond to the different experimental tests performed at the Laboratory of Energy Systems at the University of Naples "Parthenope", while the lines represent the average value, computed over all the repeated tests.

The hydrogen necessary for the operation of the fuel cell is chemically stored within metal hydrates, inside low-pressure canisters. Hydrogen purity is $99.999 \%$ and the charge process of the canisters is performed within the Lab (see Fig. 2). The charge phase is an exothermic process: thus, to increase the effective storage efficiency, the canisters need to be cooled during the accumulation process. The charging pressure is limited to 5 bars: this allows an efficient and safe storage of hydrogen, which is particularly suited for cycling applications. Table 3 reports the main parameters of the adopted canisters. 
Table 3. Main physical parameters of the chosen Ovonics canisters.

\begin{tabular}{l|l}
\hline Type & $85 \mathrm{G} 555 \mathrm{~B}-\mathrm{NTP}$ \\
$\mathrm{H}_{2}$ nominal storage capacity & $68 \mathrm{~g} / 760 \mathrm{stl}$ \\
Rated discharge & $6.0 \mathrm{slpm} / 600 \mathrm{~W}$ \\
Refilling time & $\sim 8 \mathrm{~h}$ at 17 bar and ambient temperature \\
Operating temperature & $0-75^{\circ} \mathrm{C}$ \\
Storage temperature & $-29-54^{\circ} \mathrm{C}$ \\
Diameter & $89 \mathrm{~mm}$ \\
Length & $384 \mathrm{~mm}$ with coupling $419 \mathrm{~mm}$ \\
Weight & $6.5 \mathrm{~kg}$ \\
\hline &
\end{tabular}

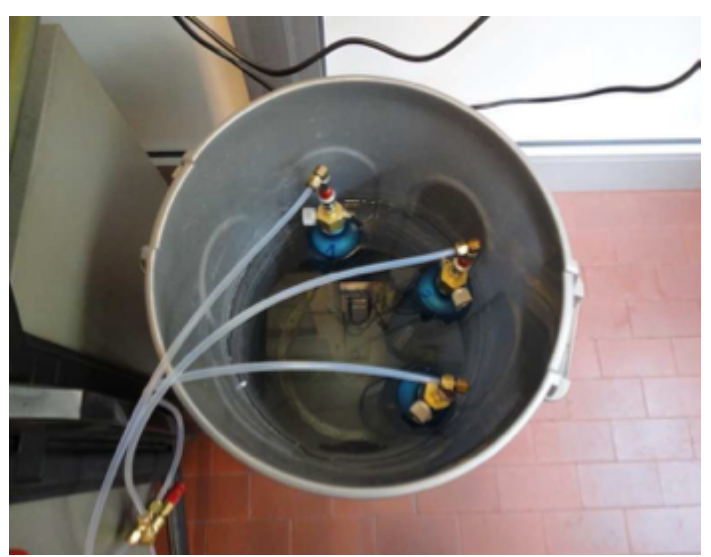

Figure 2. Charge process of the Ovonics canisters used to store the $\mathrm{H}_{2}$ used in our fuel cells. Since the accumulation is an exothermic process, to maximize the storage efficiency the canister temperature needs to be kept constant at $\sim 20^{\circ} \mathrm{C}$.

\section{Methodology}

In this Section, the developed methodology to compare traditional cars, bus, E-bike and FC-bikes will be described. The comparison will be carried out considering three basic aspects: the environmental impact in terms of pollutant emission, the accessibility in terms of comprehensive time to perform a selected route and the specific energy consumption of the different proposed solutions.

Table 4. The Table summarizes the use phase of the different vehicles considered in this work, highlighting the environmental impact of the different solutions.

\begin{tabular}{lccccccc}
\hline \hline Use Phase & $\begin{array}{c}\text { PM2.5 } \\
{[\mathrm{g} / \mathrm{km}]}\end{array}$ & $\begin{array}{c}\text { PM10 } \\
{[\mathrm{g} / \mathrm{km}]}\end{array}$ & $\begin{array}{c}\mathbf{N O}_{x} \\
{[\mathrm{~g} / \mathrm{km}]}\end{array}$ & $\begin{array}{c}\text { COV } \\
{[\mathrm{g} / \mathrm{km}]}\end{array}$ & $\begin{array}{c}\text { CO } \\
{[\mathrm{g} / \mathrm{km}]}\end{array}$ & $\begin{array}{c}\mathbf{C O}_{2} \\
{[\mathrm{~g} / \mathrm{km}]}\end{array}$ & $\begin{array}{c}\text { Consumption } \\
{[\mathrm{kJ} / \mathrm{km}]}\end{array}$ \\
\hline Bus & 0.17 & 0.21 & 8.51 & 0.46 & 1.80 & 703.95 & 7471.80 \\
Car & 0.14 & 0.05 & 0.48 & 0.15 & 1.38 & 197.11 & 2116.56 \\
E-bike & 0.00 & 0.00 & 0.00 & 0.00 & 0.00 & 5.82 & 45.55 \\
FC1-bike & 0.00 & 0.00 & 0.00 & 0.00 & 0.00 & 7.53 & 58.97 \\
FC2-bike & 0.00 & 0.00 & 0.00 & 0.00 & 0.00 & 1.41 & 25.57 \\
\hline \hline
\end{tabular}




\subsection{Environmental Assessment}

3.1.1. Car

Personal cars consumption and pollutant emissions have been evaluated with reference to the specific stock of cars on the roads of the Italian city Viterbo. These data are therefore strictly linked to the characteristics of the circulating vehicle fleet in the region under examination. Nevertheless, the derived results can be considered reasonably representative of the Italian situation. In particular, from the SEAP of Viterbo [10], it was possible evaluate the number of private cars registered in the Municipality (year 2014) classified by type (diesel, petrol, LPG or methane) and by pollution class. Starting from the pollutant emissions of each car category, considering the weighted average of all the cars, pollutant emissions of a reference car have been calculated. Results are reported in Table 4.

\subsubsection{Bus}

Generally speaking, in Italy, the vast majority of buses use Diesel internal combustion engines. As a consequence, local emissions, greenhouse gas emissions and energy use are highly related to fuel efficiency, vehicle power, loading and operating modes and fuel quantity. Accordingly, most buses have very different emissions per kilometres rates, depending on several factors as pollution class and year of production. The public transport service in Viterbo is managed by Francigena Srl - Multiservice Society. The vehicle fleet of Francigena is characterized by an average age of vehicles of about 18 years and, therefore, by a pollutant Euro 2 class. From the Sinanet portal (the National environmental network information system), the requested data for this category of diesel Euro 2 bus, weighing less than 15 ton, have been calculated and data reported in Table 4.

\subsubsection{E-bike}

The analysis has been carried out on a specific model of e-bikes named HYBRID 24, with a 250 $\mathrm{W}$ engine and a top speed of $25 \mathrm{~km} / \mathrm{h}$. It is caharcterized by an autonomy of $12 \mathrm{~h}$ and $300 \mathrm{~km}$. As already remarked, pollutant emissions at the point of use were considered void. Starting from the battery characteristics $(360 \mathrm{Wh})$, the average autonomy $(70 \mathrm{~km})$ and the national energy mix (see Tab. 1) energy consumption have been evaluated. Finally the $\mathrm{CO}_{2}$ emissions for kilometer traveled have been calculated considering an emission factor of $0.128 \mathrm{~g}$ of $\mathrm{CO}_{2}$ per $\mathrm{kJ}, 1$.

\subsubsection{FC-bikes}

Our FCB employs the same engine as the HYBRID 24 EB model The assessment of consumption and emissions was made considering two ways of hydrogen production: electrolysis (FC1-bike), characterized by an overall $\eta=0.8$ efficiency and steam reforming (FC2-bike), characterized by an overall efficiency of $\eta=0.75$. Starting from these data, the emissions and consumption for both types of $\mathrm{H}_{2}$ production have been calculated and reported in Table 4. All fuel cell data were experimentally evaluated, as described in the previous Sections.

\subsection{Health Impact}

To quantify the environmental impact, different kinds of indicators are eligible, and can be categorized into two groups: problem-oriented (mid-points) and damage-oriented (end-points), [18]. The first group classifies impacts into environmental themes such as global warming potential, acidification potential, ozone depletion potential, etc. This method generates a more complete picture of the ecological impact, but requires some knowledge of the life-cycle analysis (LCA) to interpret the results, [19]. The second group translates environmental impacts into issues of concern such as human health, natural environment and resources. Within this research the Eco-indicator 99 is used, a damage- oriented method. By this method, the damage caused to human health, ecosystem quality and resources is calculated. In particular, Eco-Indicator 99 takes into proper consideration: 
1. diffusivity, that correlates the specific pollutant substance emitted in atmosphere with its temporal concentration variabilty;

2. exposition, the correlation between the variable concentration of pollutants in time and human exposure;

3. impact of all the previous effects on the human health.

The final result of the damage analysis is evaluated as life years lost due to the exposition to that specific toxic substance. With regards to the pollutant substances considered in this research, Table 5 reports the damage values in [daily loss $/ \mathrm{kg}$ ] for the pollutants considered in this work, [20]. The third column reports the values of the daily loss $/ \mathrm{kg}$ related to that of the $\mathrm{NO}_{x}$, which is taken as the reference value. This means, for example, that the PM2.5 non-dimensional damage impact is $\sim 8$ times that of $\mathrm{NO}_{x}$.

Table 5. Damage values for the different considered pollutants; the third column reports the values of the daily loss $/ \mathrm{kg}$ related to that of the $\mathrm{NO}_{x}$, which is taken as the reference value.

\begin{tabular}{lcc}
\hline \hline Pollutant & [daily loss $/ \mathrm{kg}]$ & $\begin{array}{c}\text { non-dimensional } \\
\text { daily loss } / \mathrm{kg}[-]\end{array}$ \\
\hline PM2.5 & $7.10 \times 10^{-4}$ & 8.004509583 \\
PM10 & $3.75 \times 10^{-4}$ & 4.227733935 \\
COV & $1.72 \times 10^{-4}$ & 1.939120631 \\
CO & $3.22 \times 10^{-7}$ & 0.003630214 \\
NOx & $8.87 \times 10^{-5}$ & 1.000000000 \\
\hline \hline
\end{tabular}

\subsection{Accessibility and Mobility}

The primary benefit of any transportation mode is the increase in mobility and accessibility. Considering an EB, it provides much higher levels of mobility and thus accessibility with respect to bus or private car. Mobility and accessibility are dependent upon the urban layout and transportation infrastructure. The difference in the mobility values of the different transportation solutions can be ascribed to the (relative) ease of movement or to the operating speeds of the transport solution. Accessibility is defined as the number of transport opportunities made available within a given travel time. Accessibility can be improved by proximity (e.g. job-house distance) or mobility, which is determined by transportation system operations and vehicle performance characteristics. Job accessibility has been identified as a major contributor to poverty in developing countries and it plays a major role in the development of any transportation policy, [21].

\section{Results}

\subsection{Routes}

Eight routes, typical for University students are taken into account, as highlighted in Fig. 3. The environmental impact and the accessibility of each of the following vehicles are taken into account: car, bus, E-bike and FC-bike. An average of 1.5 people for private cars and 15 people in the buses is assumed. The routes are:

1. Porta Fiorentina Station - School of Economics, Engineering and Enterprise (DEIM);

2. Porta Fiorentina Station - Engineering Building;

3. Student's House-DEIM;

4. DEIM - Student's House;

5. Engineering Building - Student's House;

6. Student's House - Engineering Building;

7. Student's House - Rector's Building;

8. Rector's Building - Student's House. 


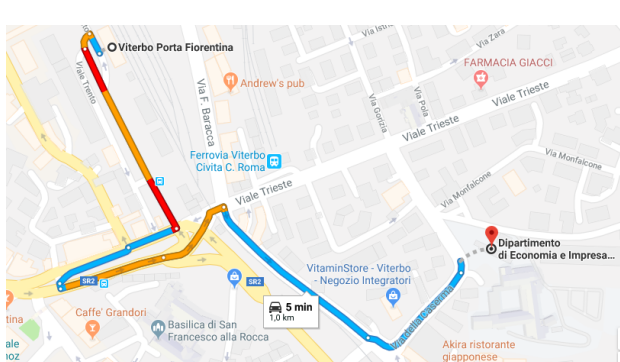

(a) Route 1

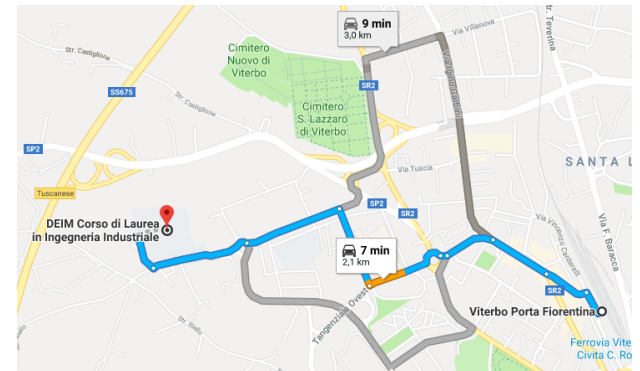

(b) Route 2

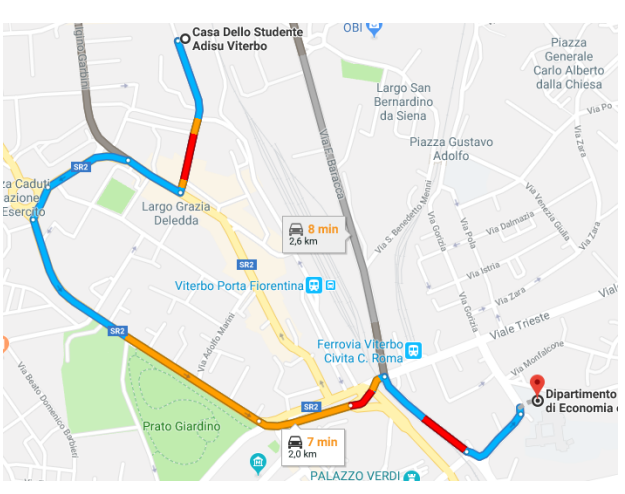

(c) Route 3

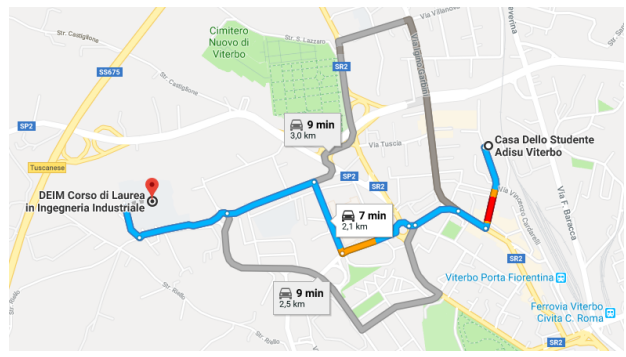

(e) Route 5

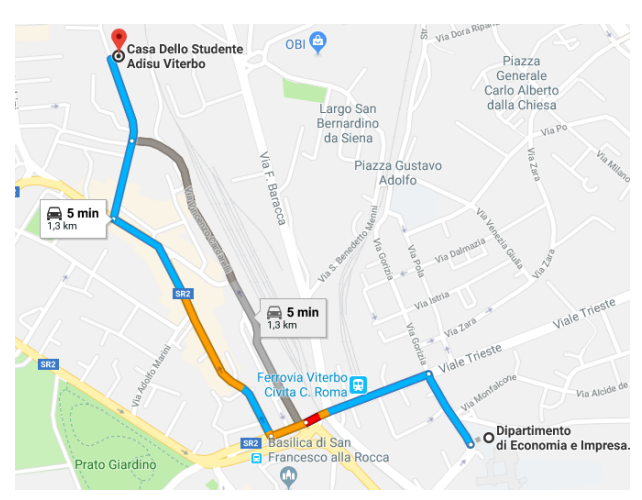

(d) Route 4

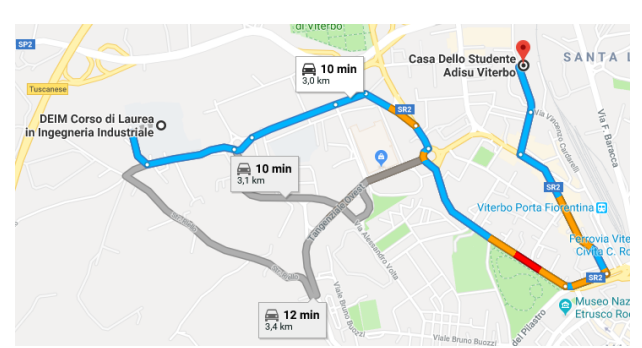

(f) Route 6

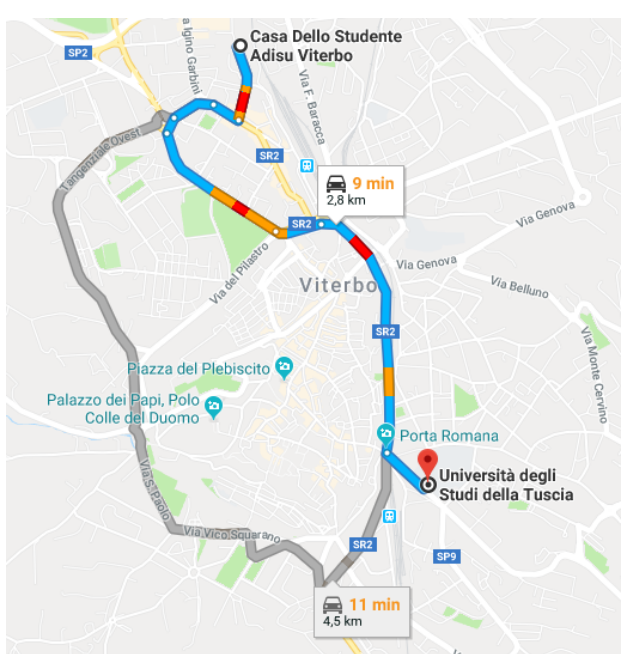

(g) Route 7

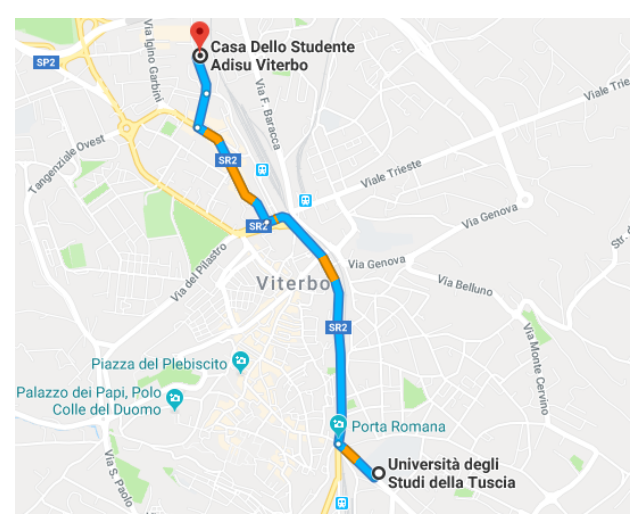

(h) Route 8

Figure 3. Routes considered in the present work. 


\subsection{Pollutant Emissions}

To assess the environmental impact of the different solutions, we have assumed that the Routes in the previous Section are covered across 200 working days per year. For each of the considered vehicles, emissions and fuel consumption are evaluated considering the number of possible users: one user for the bikes, 1.5 for the cars and 15 for the buses. For the last two vehicles an errorbar of $1 \div 3$ users for the cars and $10 \div 20$ for the buses are considered. The histograms in Fig. 4 report the total amount of pollutant emissions for the different solutions.

According to the panels in Fig. 4, it is apparent that the adoption of passenger cars delivers the worst performance in terms of PM2.5, PM10, COV and CO emissons. The buses exceed the levels emitted by passenger cars only for the NOx pollutant, which is in agreement with what expected due to the type of employed engines in public transportation in Viterbo area. Interestingly, the E-bike and FC1-bike deliver very similar performance, while FC2-bike emerges as the least polluting solution, among those evaluated in this work. The production of $\mathrm{H}_{2}$ through reforming, in fact, provides low levels of total pollutant emissions, which are sensibly lower than those related to the electrolytic process.

\subsection{Environmental and Health Impact}

For all the vehicles considered in this work, a bubble diagram is presented, in which three indexes are reported: consumption $[\mathrm{kJ} / \mathrm{km}$ ] on the abscissas; an accessibility index on the ordinates, which accounts for the time related to waiting and covering an average route of $2.5 \mathrm{~km}$. The diameter of the bubbles is linked to the environmental and human health impact index, for the various transport solutions. To evaluate the diameter of the bubbles in Fig. 5, the Eco-indicator 99 has been used.

The final damage analysis is performed considering the years of life lost (YLL) due to the exposition to the various pollutants, according to the values reported in Tab. 5.

Table 6 reports the environmental index for the different vehicles considered in the present work, while Fig. 5 shows the bubble diagram computed according to the described procedure.

To realize the bubble diagram in Fig. 5, starting from the values in the third column of Tab. 5, the environmental index providing the diameter of each bubble has been computed as

$$
D_{b, i}=\sum_{\text {species }}[\text { Pollutant Concentration }] \times \text { Non }- \text { dimensional daily loss } / \mathrm{kg}
$$

with $i$ spanning on the different vehicles considered in this work. The diameter of the bubbles are reported in Tab. 6. It is interesting to notice that the bubble diagram in Fig. 5 provides almost the same result for bus and passenger cars, which is due to the lower emission standard of the public transportation vehicles employed in Viterbo area.

Table 6. Environmental index $\left(D_{b}\right)$ for the various vehicles considered in the present work. To be noted, the EI of the E-bike, FC1-bike and FC2-bike is 0.0.

\begin{tabular}{lccc}
\hline \hline & Consumption $[\mathrm{kJ} / \mathrm{kg}]$ & Accessibility [min] & Environmental Index $D_{b}$ \\
\hline Bus & 498 & 28 & 0.9 \\
Car & 1411 & 8 & 1.0 \\
E-bike & 46 & 5 & 0.0 \\
FC1-bike & 59 & 5 & 0.0 \\
FC2-bike & 26 & 5 & 0.0 \\
\hline \hline
\end{tabular}

\section{Conclusions}

E-bikes are relatively energy efficient and emit no tailpipe emissions which is a big advantage in urban areas. When compared to buses, e-bikes perform well during the use phase but not so well 
Bus $\square$ Cars E-bike $\square$ FC1-bike $\quad$ FC2-bike

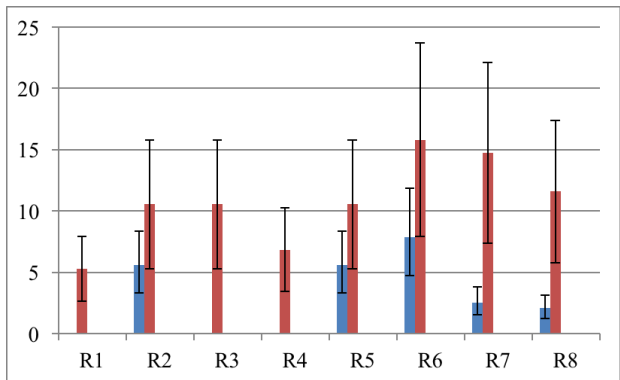

(a) PM2.5

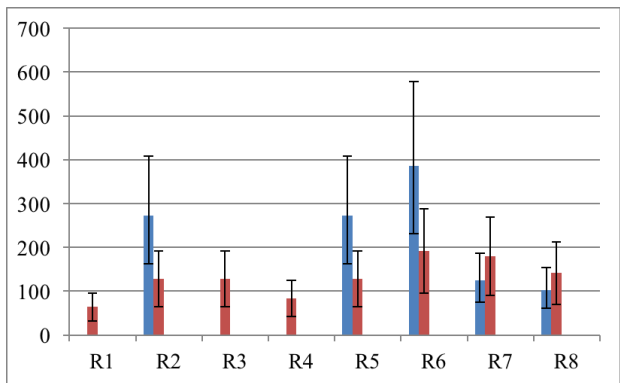

(c) Nox

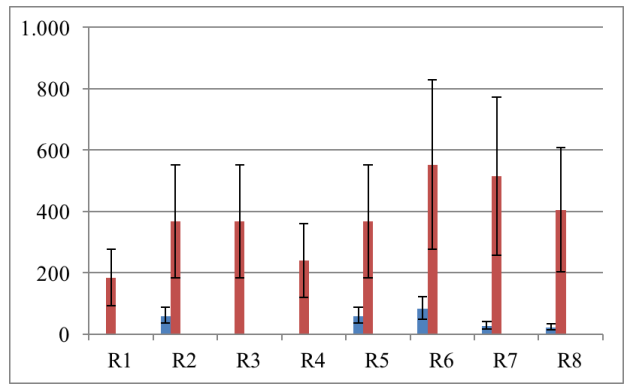

(e) $\mathrm{CO}$

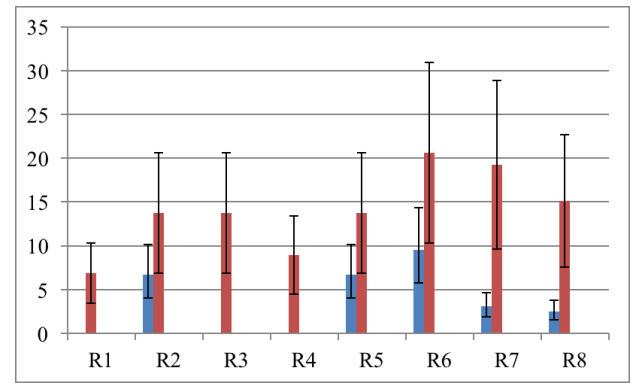

(b) PM10

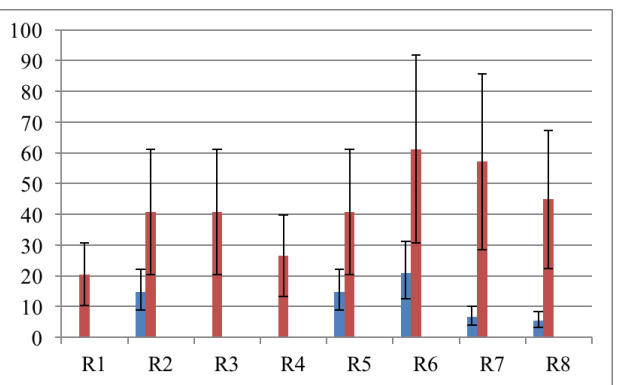

(d) $\mathrm{COV}$

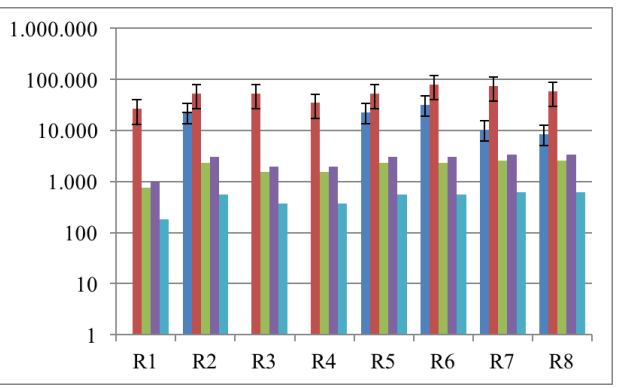

(f) $\mathrm{CO}_{2}$

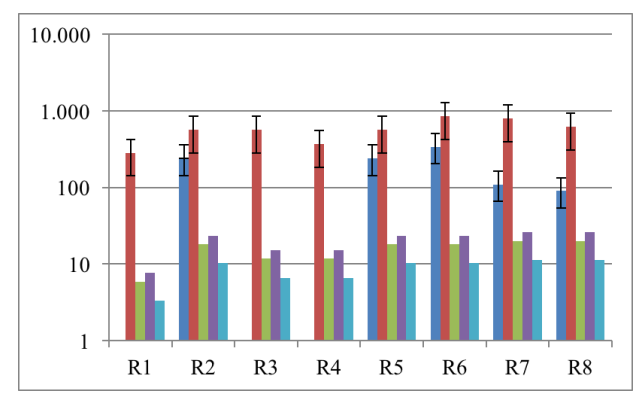

(g) Consumption

Figure 4. Comparison between the emissions (a) to (f) and consumption ( $g$ ) for the different technological solutions explored in the present work. From (a) to (f), the quantities are expressed in [g/year]; fuel consumption in panel $(\mathrm{g})$ is expressed in [MJ/year]. 


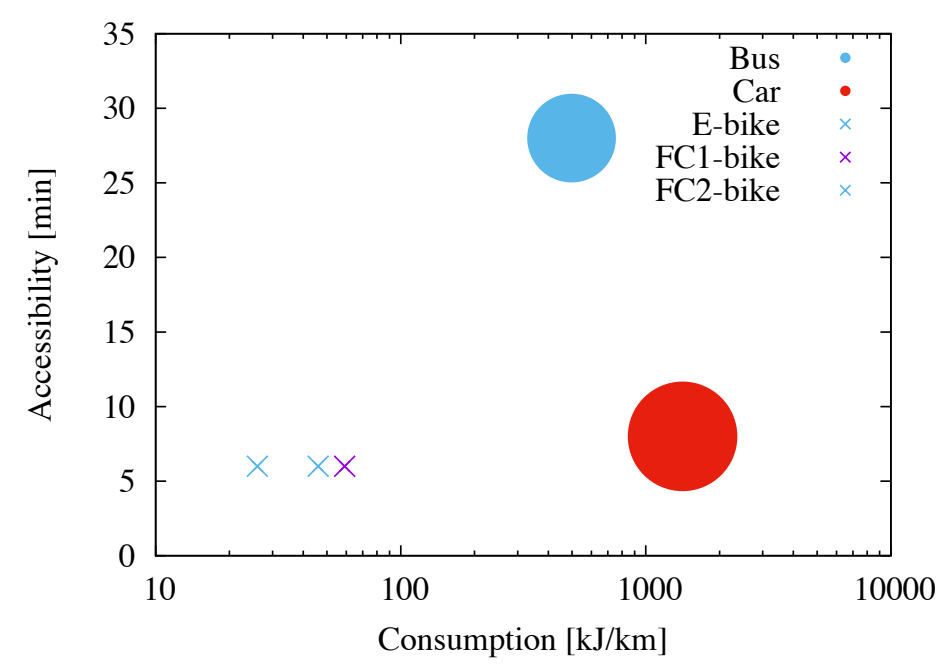

Figure 5. Bubble diagram showing the health impact of the different technologies. The Figure highlights that in the Viterbo area, there is not an appreciable difference in employing cars or buses, from a human-health impact point of view.

when comparing the life-cycle emissions speaking about PM 10 and $\mathrm{SO}_{x}$ emissions. Electric bikes have low usable lifespans so all of the impacts of production of the vehicle are spread over a low number of passenger kilometers $\left(\sim 5 \times 10^{4}\right)$. Buses are much larger and have more environmental impacts per vehicle, but those impacts are spread over a large number of passengers kilometers $\left(\sim 5 \times 10^{7}\right)$. The impacts of the production processes are not borne by the users of the system, but the resident nearby industrial facilities. Environmentally, bicycles perform best of all modes, with low energy use and greenhouse gas emissions, but comparable NOx and SOx emissions as buses over the life-cycle.

The biggest benefit of e-bikes is increased mobility and thus accessibility to all types of opportunities in the urban areas. Buses have very low levels of mobility, especially for short trips where most of the travel time is spent accessing bus stops and waiting. E-bikes provide very cost effective personal mobility that is unmatched by any mode in the transportation system. While this mobility might lead to longer trip lengths and thus more externalities it also leads to more opportunities of urban low income individuals. Bicycles also perform well because of their flexibility and segregation from congested traffic.

Author Contributions: L.A. envisioned the research; G.F. performed the experimental tests, analyzed the results and wrote the paper; A.L.F. helped in the discussion of the results and the writing. All Authors have reviewed the manuscript.

Acknowledgments: Fruitful and inspiring discussions with Prof. Stefano Ubertini and Dr. Vesselin K. Krastev are kindly acknowledged. This research has been partially supported by the Italian Ministry Program PRIN, grant $n$. 20154EHYW9, with Prof. Chiara Biscarini as the Principal Investigator.

Conflicts of Interest: The authors declare no conflict of interest.

\section{References}

1. Greenhouse Gas Emissions from a Typical Passenger Vehicle United States Environmental Protection Agency EPA Web Archive 2017 https://www.epa.gov/greenvehicles/greenhouse-gas-emissions-typical-passenger-vehicle

2. Transport Briefing, https://www.eea.europa.eu/soer-2015/europe/transport, European Environment Agency, 2015;

3. Policy Options for Reducing Energy Use and Greenhouse Gas Emissions from U.S ... Di National Research Council (U.S.). Committee for a Study of Potential Energy Savings and Greenhouse Gas Reductions from Transportation, 2011 
4. Handy, S.L., Xing, Y., Buehler, T.J., 2010. Factors associated with bicycle ownership and use: a study of six small U.S. cities. Transportation 37, 967-985. doi:10.1007/s11116-010-9269-x.

5. Jannelli, N., Nastro, R.A., Cigolotti, V., Minutillo, M. and Falcucci, G., 2017. Low pH, high salinity: Too much for microbial fuel cells? Applied Energy, 192, pp.543-550.

6. Krastev, V.K., Falcucci, G., Jannelli, E., Minutillo, M. and Cozzolino, R., 2014. 3D CFD modeling and experimental characterization of HT PEM fuel cells at different anode gas compositions. International Journal of Hydrogen Energy, 39(36), pp.21663-21672.

7. Montessori, A. \& Falcucci, G. Lattice Boltzmann Modeling of Complex Flows for Engineering Applications Morgan \& Claypool Publishers, 2018.

8. M. Lott, Why EV's can reduce (but not eliminate) urban air pollution,

9. Ventsislav Keseev, Grigor Mihaylov Competitiveness of Electric Vehicles, Electronics and Telecommunications (ISETC) 2016, 12th IEE Symposium DOI: 10.1109/ISETC.2016.7781043

10. https://www.comune.viterbo.it/viterbo/attachments/article/456/PAES_PDF.pdf

11. Troy R. Hawkins, Bhawna Singh, Guillaume Majeau-Bettez, Anders Hammer Str ømman (2012) Comparative Environmental Life Cycle Assessment of Conventional and Electric Vehicles doi: 10.1111/j.1530-9290.2012.00532.x , Journal of Industrial Ecology

12. Cherry, C., Weinert, J. and Ma, C., 2007. Environmental impacts of e-bikes in Chinese cities. California, Estados Unidos: UC Berkeley Center for Future Urban Transport.

13. Chan, The State of the Art of Electric, Hybrid, and Fuel Cell Vehicles Proceedings of the IEEE 2007

14. M. Weiss, P. Dekker, A. Moro, H. Scholz, M. K.Patel (2015) On the electrification of road transportation - A review of the environmental, economic, and social performance of electric two-wheelers. Transportation Research, https://doi.org/10.1016/j.trd.2015.09.007

15. G. J. Offer et Al., “Comparative Analysis of Battery Electric, Hydrogen Fuel Cell and Hybrid Vehicles in a Future Sustainable Road Transport System", Energy Policy 38, 242010

16. M. Granovskii, I. Dincer, and M. A. Rosen, "Economic and Environmental Comparison of Conventional, Hybrid, Electric and Hydrogen Fuel Cell Vehicles," J. Power Sources 159, 1186 (2006), doi.org/10.1016/j.jpowsour.2005.11.086

17. http://www.h2planet.eu/en/detail/H500

18. O. Ortiz, F. Catsells, G. Sonnemann, Sustainability in the construction indus- try: a review of recent developments based on LCA, Construction and Building Materials 23 (2009) 28-39.

19. G.A. Blengini, (2008) Life cycle of buildings, demolition and recycling potential: a case study in Turin, Italy, Building and Environment 44 (2009) 319-330.

20. 99,E indicator: Method for assessing the damage (LCA), 2015

21. World Bank (2002) Cities in the Move: A World Bank Urban Transport Strategy Review. 